\title{
Effect of Steel Fiber on Properties of High Performance No-Fine Concrete
}

\author{
Nada M. F. Alwaan ${ }^{1 *}$ \\ ${ }^{1}$ Department of Civil engineering, University of Baghdad, Iraq \\ *Corresponding author E-mail: nada.aljalawi@coeng.uobaghdad.edu.iq
}

\begin{abstract}
No-fine concrete (NFC) is cellular concrete and it's light weight concrete produced with the exclusion of sand from the concrete. This study includes the mechanical properties of lightweight reinforced by steel fiber, containing different proportions of steel fiber. This study was done using number of tests. These tests were density, compressive strength, flexural strength and absorption. These tests of the molds at different curing time. The results of tests that implication of fiber to No. fine concrete did not affect significantly on the compressive strength, While the flexural strength were gets better. Results explained that, the flexural strength of (1\%) fiber No- fine concrete molds are four times that of the reference molds in age 28 days. The growing in flexural strength for fiber reinforced mixes with fiber by vol. $(0.5 \%, 0.75 \%, 1 \%)$ were $(78 \%, 132 \%, 286 \%)$ respectively at age of 28 days.
\end{abstract}

Keywords: absorption, compressive strength, flexural strength, no fine, steel fiber.

\section{Introduction}

General (Schaefer V. R et al 2006) limited researches have been carried out to study the mechanical properties of fiber reinforced no-fine concrete. ASTM C330 2017 this covers light weight aggregate intended for use in structure concrete in which prime considerations are reducing the density while maintaining the compressive strength of the concrete. Procedures covered in this specification are not intended for job control of concrete. Two general types of light weight aggregates are covered by this specification: aggregate prepared by expanding, pelletizing, or sintering, product such as blast-furnace slag, clay, diatomite, fly ash, shale or slate and aggregate prepared by processing natural materials, such as pumice, scoria, or tuff. The aggregates shall be composed predominately of light weight-cellular and granular inorganic material. Light weight aggregate shall be tested, and should not contain excessive amounts of deleterious substances, and should conform to the specified values of organic impurities, aggregate staining, aggregate loss of ignition, clay lumps and friable particles, loose bulk density, compressive strength, drying shrinkage, and resistance to freezing and thawing.

Advantages of no-fine concrete

1. No-fine concrete are low cost materials, somewhat higher thermal insulating values, lower shrinkage and lower unit weight. 2.lower density of no fine concrete $(1600-2000 \mathrm{Kg} / \mathrm{m} 3)$.

3. Low cost because of low cement, high insulation of no fine.

4. No separation and capillary movement of water (Abadjieva,T et al 2000)

Disadvantage of no-fine concrete: The major disadvantages are its lower flexural, compressive and bond strength and higher permeability(Akihama,S et al 1984).
Objective of the research: The aim of paper was to study the properties of no fine concrete for construction industry as cost walls in low-rise, low cost building.

Applications for no-fine concrete: The use of no-fines concrete is in load-bearing walls in local building and in in-filling panels in framed structures (Brown, $R$ et al 2002).

Review of Literatures

General

Classification of lightweight concrete: The density of concrete can be minimize by placing some of the solid material in the mix by air gaps. There are three possible locations of the air:

1-In the aggregate particles, which are known as light weight aggregate.

2- The resulting concrete being recognized as cellular concrete.

3-Between the gravel particles, the sand being negligent, in order to made new concrete is known no-fine concrete.

Concrete made with light weight aggregate is known as light weight aggregate concrete, made is a particular group of light weight concrete.

Characteristics of any type of concrete reinforced by steel fibers:

Below are some characteristics that the use of steel fibers can safely improve:

1- Modulus of rupture can be increased of up to 3 times more compared to normal concrete.

2-Impedance of fatigue increase 1/2 times increase compared with normal.

3-Impact impedance: - Greater impedance to damage in case of a heavy impact.

4- Permeability:-The material is less spongy.

5- Abrasion impedance: - More effective composition against abrasion.

6- min. Shrinking 7- Low Corrosion.

(Rehman H.A.A 2012), (Muttar,A.A. 2013) Explain in study the mechanical properties of no-fines concrete with or without steel fibers are investigated. The effect of mixture proportion on compressive strength, tensile strength and density presented. 
(Balendran R.V et al 2002) the results of experiments the effectiveness of fiber inclusion in the improvement of mechanical performance of concrete with consideration to concrete type and specimen size.

(Chen B. et al 2004) the expanded polystyrene concrete is a low weight, low strength material with good energy-absorption characteristics. However, due to the low weight of EPS and their hydrophobic surface, this concrete is prone to segregation during molding, which results in poor workability and lower strength.

\section{Materials and Methods}

General: The present work is to research the effect of steel fiber on the high performance no-fine concrete. This chapter explained their properties of materials were used, experimental work and the methods adopted in preparation and testing of specimens. The experimental work consists of two parts. In the first one, details on the constituent materials are used; mix proportions and preparation of fresh concrete used in the study a represented including process used in the study a represented including process for determining basic physical, mechanical characteristics of concrete.

Materials: In this section, the types of materials are used in experimental part and their properties are described as follow:

Cement: Used in this work traditional cement. This cement is complied with the (Iraqi Quality Standard No.5/1984).

Gravel: Gravel were used with a nominal size (5-14) $\mathrm{mm}$. This type of gravel was in the limits (Iraqi Quality Standard No.45 /1984).

Water: Clean water was used for casting and curing.

Silica Fume: Silica fume is accidental output of production silica metal with high reactive pozolan. Fume silica is available to produce high strength lightweight concrete. Silica fume has good physical and chemical properties like high fineness, low $\mathrm{SO}_{3}$.Silica fume was used as a pozolan in concrete. Silica fume is obtained from local markets which are of German origin.

The SF conforms to the requirement of (ASTM C 1240 2016).

Super Plasticizers: (Neville A.M 2010) it is a sort of chemical additives decrease water if it decrease the amount of mixing water required to produce homogenous concrete with a certain strength of $12 \%$ at least and denote (HRWRA), because it is the material refined Lignosulfonate which are used in large amount (Up to 10 times more than decrease the usual additives for water) in the blend of the concrete without causing side effect such as delaying the freezing lightweight concrete significantly.

Plasticizers are superior on four sorts.

- Salts Sulfonates Formldehid or (MSF) and behave of chlorides is equal to 0.005 .

- Salts of Naphthalene Sulfonic Formldehid (NSF).

- Lignosulfonate. Since forties was used Lignosulfonate as a reducer of water and relatively low cost. Material consists Lignosulfonate like other super plasticizers of molecular units concatenated key.

- Carboxed Acrylic Ester copolymer or CAE.

The physicist effect of plasticizers superior is to prevent soft particles of the conglomerates, as a result of the interactions Electrostatic (electro-static), the plasticizer superior particles are attracted towards the surfaces of granulated cement and lead it to generate strong repulsion responsible for dispersed conglomerate, where reduce plasticizer superior of the density or thickness of the layer water thin around the cement particles to overcome adhesion powers and change the surface charges and thus increase the operability and give the design of high mixture high liquidity .

Super plasticizer was used in this research is added to the water reduce degree superior and commercially known (Sika ViscoCrete-5930) $\mathrm{PC}(200)$ which is different from the plasticizer superior because it has a coefficient of viscosity as it is composed of (Carboxylic Ether Polymer) conforms to the requirement of (ASTM C $\leqslant$ 9 2017).
Steel Fiber :( ACI 544 2009) there are many type of fiber: Steel fiber, Glass fibers, wood fiber, leaf of palm and Polypropylene fibers.

Aspect ratio defined as the fiber length divided by diameter. Representative aspect ratio between 30 to 150 for length and 6 to 75 $\mathrm{mm}$ for an equivalent dia.

(Henger, C. H 1981) the use of fibers expected to save time, decrease the overall cost of the project. It is also possible to save money on the material cost, especially if the cost of steel elevation to levels similar to those in 2008 . The decrease in the overall cost of the project makes the use of fibers attractive as similar product is gained for less cost.

In this research, steel fiber mixed with mortar by different percentage $(0.5,0.75,1) \%$. The properties of used steel fiber is shown in table 1

Table 1: Properties of steel fibers

\begin{tabular}{|l|l|}
\hline Property & Specification \\
\hline Density & $7860 \mathrm{Kg} / \mathrm{m}^{3}$ \\
\hline Ultimate strength & $\varsigma 0 \cdot \mathrm{MPa}$ \\
\hline Modulus of elasticity & $200 \times 10^{3}$ \\
\hline Length & $50 \mathrm{~mm}$ \\
\hline Diameter & $0.9 \mathrm{~mm}$ \\
\hline Aspect ratio & 55.55 \\
\hline
\end{tabular}

Testing of Hardened concrete

Destructive and non-destructive tests were carried out on a hardened specimen as follows:

Destructive Tests:

Compressive Strength Test: This test was carried out according to the (ASTM C116 1999) as equivalent cube on $(100 * 100 * 100)$ $\mathrm{mm}$ prism, using the (TINIUS OLESN) testing machine of (200000 LBS $=909 \mathrm{KN}$ ) capacity. The cube were tested at the curing time (7, 28 and 90) days.

Flexural strength: The flexural was carried out according to (ASTM C 293 2006) using (TINIUS OLESN) testing machine. It was calculated using the formula at the age 7,28 and 90 age :

$\mathrm{Fr}=3 \mathrm{PL} / 2 \mathrm{BD}^{2}$

Non-Destructive Test: In this work the density and absorption were used to monitor variations in compressive strength and other properties of hardened concrete.

Density Test: This test was carried out according to (ASTM C642 2013) .

Absorption Test: This test was carried out according to (British Standard B.S. 1881-Part 122 1983).

Mix Design: Design of no fine concrete according compressive strength of $15 \mathrm{MPa}$ at 28 days, are made according to trail and error. The cement content is $\left(400 \mathrm{Kg} / \mathrm{m}^{3}\right)$ and $\mathrm{W} / \mathrm{C}$ ratio is $(0.4)$. The slump required for all mixes is $(50 \mathrm{~mm})$. Silica fume were used at $10 \%$ by weight of cement. These mixes have been studied by adding different percentage of steel fiber with mortar of $(0.5$, $0.75,1) \%$, and then its effect on properties of concrete at age of 7 , 28,90 days.

\section{Results and Discussion}

\section{General}

The experimental work are presented and analyzed. All the results are presented in Tables and Plots.

\section{Results}

Compressive strength: The compressive strength slight increase for all kinds of mixes show in Table 2. Test results explain above, ref. concrete and with steel fiber molds present continuous slight increase in strength up to 7, 28 and 90 days of curing. Show improvement in strength for mixes with fibers. There was increase in the compressive strength with increasing the fiber by vol. 
Table 2: Compressive Strength results

\begin{tabular}{|c|c|c|c|}
\hline \multirow{2}{*}{ Mix symbol (with steel fiber \%) } & \multicolumn{3}{|c|}{ Compressive strength (MPa) } \\
\cline { 2 - 4 } & $\mathbf{7}$ day & $\mathbf{2 8}$ day & $\mathbf{9 0}$ day \\
\hline 0 & 12.0 & 18.0 & 22.0 \\
\hline 0.5 & 17.0 & 20.0 & 25.6 \\
\hline 0.75 & 19.0 & 23.0 & 29.50 \\
\hline 1.0 & 20.0 & 24.50 & 30.60 \\
\hline
\end{tabular}

Flexural Strength: The influence of fiber content on the flexural strength for all proportion of steel fiber reinforced concrete specimens is presented in Table 3 The result indicated that, the flexural strength of $(1 \%)$ steel fiber reinforced no fine concrete molds are higher than reinforced reference concrete molds, at age 28 days.

Table 3: Flexural Strength results

\begin{tabular}{|c|c|c|c|}
\hline \multirow{2}{*}{ Mix symbol (with steel fiber \%) } & \multicolumn{3}{|c|}{ Flexural Strength $(\mathrm{MPa})$} \\
\cline { 2 - 4 } & $\mathbf{7}$ day & 28 day & $\mathbf{9 0}$ day \\
\hline 0 & 4.50 & 5.0 & 5.20 \\
\hline 0.5 & 7.50 & 8.90 & 11.30 \\
\hline 0.75 & 9.0 & 11.60 & 14.60 \\
\hline 1.0 & 16.0 & 19.30 & 29.50 \\
\hline
\end{tabular}

Absorption: The absorption increase for all kinds of mixes is show in Table 4. Test results explain that reference concrete and concrete with steel fiber molds present continuous increase in absorption up to (7, 28 and 90) days. Results show reference concrete without fiber have lower absorption than fiber reinforced reference concrete mixes containing (1\%) steel fiber. When The fiber volume fraction increase the voids content increase. The high voids content to have a negative effect on the absorption.

Table4: absorption results.

\begin{tabular}{|c|c|c|c|}
\hline \multirow{2}{*}{ Mix symbol (with steel fiber \%) } & \multicolumn{3}{|c|}{ Absorption $(\%)$} \\
\cline { 2 - 4 } & $\mathbf{7}$ day & $\mathbf{2 8}$ day & $\mathbf{9 0}$ day \\
\hline 0 & 3.50 & 2.80 & 2.0 \\
\hline 0.5 & 3.60 & 3.0 & 2.30 \\
\hline 0.75 & 3.70 & 3.30 & 2.60 \\
\hline 1.0 & 3.80 & 3.40 & 2.80 \\
\hline
\end{tabular}

Density test: The 7, 28 and 90 day air dry density of all types of concrete mixtures is presented in Table 5. Results show that the 7, 28 and 90 days. For structural no fine concrete, the densities should be between (1950-2110) $\mathrm{Kg} / \mathrm{m}^{3}$, however all mixes conform to the requirements of (LWC) according to ACI the maximum density to $2110 \mathrm{Kg} / \mathrm{m}^{3}$ were $1 \%$ steel fiber at 90 days. Results show that (NFC) mixes without fibers have lower density than fiber reinforced (NFC) mixes containing (1\%) steel fiber.

Table5: Density results

\begin{tabular}{|c|c|r|r|}
\hline \multirow{2}{*}{ Mix symbol (with steel fiber \%) } & \multicolumn{3}{|c|}{ Density $\left(\mathrm{Kg} / \mathrm{m}^{3}\right)$} \\
\cline { 2 - 4 } & $\mathbf{7}$ day & $\mathbf{2 8}$ day & $\mathbf{9 0}$ day \\
\hline 0 & 1950 & 2000 & 2050 \\
\hline 0.5 & 1960 & 2010 & 2090 \\
\hline 0.75 & 1970 & 2020 & 2100 \\
\hline 1.0 & 1980 & 2025 & 2110 \\
\hline
\end{tabular}

\section{Conclusions}

Density: Results show that the reference concrete mixes without fiber have lower density than fiber reinforced concrete mixes containing (1\%) steel fiber because addition steel fiber to concrete. However, the densities should be between $(1950-2110) \mathrm{Kg} / \mathrm{m}^{3}$ were $(0 \%, 1 \%)$ of steel fiber respectively. The ratio increase in density for steel mixes with fiber by volume $(0.5 \%, 0.75 \%, 1 \%)$ were $(0.5 \%, 1 \%, 1.25 \%)$ respectively at age 28 days.

Compressive Strength: The increase in this test with increasing fiber ratio because addition steel fiber to concrete. The ratio increase in compressive strength for mixes with fiber by volume $(0.5 \%, 0.75 \%, 1 \%)$ were $(11.11 \%, 27.78 \%, 36.11 \%)$ respectively at age 28 days.

Flexural Strength: Test results indicated that, flexural strength of (1\%) steel fiber reinforced concrete molds are four times that of ref. molds. Flexural strength increase with increasing the fiber volume fraction because of high tensile strength of fiber. The per- centage increase in tensile strength for steel mixes with fiber by volume fraction of $(0.5 \%, 0.75 \%, 1 \%)$ were $(78 \%, 132 \%, 286 \%)$ respectively at age 28 days.

Absorption: Results show that the reference concrete mixes without fiber have lower absorption than fiber reinforced control concrete mixes containing (1\%) steel fiber The percentage increase in absorption for steel mixes with fiber by vol. $(0.5 \%, 0.75 \%, 1 \%)$ were $(7.14 \%, 17.86 \%, 21.43 \%)$ respectively at age 28 days

\section{References}

[1] Schaefer, V.R., M.T. Suleiman, K. Wang, (2006), "An overview of pervious concrete Applications in storm water Management and pavement system" , Iowa state university, Ames.

[2] ASTM C 330, "Standard specification for lightweight aggregates for structural concrete" 2017

[3] Abadjieva, T. and P. Sephiri(2000) "Investigations on some properties of no fines concrete" Department of civil Engineering, University of Botswana, private Bag 0061 .

[4] Akihama,S., T. Suenaga, . and T. Banno,(1984) "Mechanical properties of carbon fiber Reinforced cement composite and the Application of large Domes" Kajime Institute of construction Technology, Tokyo, Jpan.

[5] Brown,R., A.Shukla and K.R. Natarajan (2002)"Fiberrein forcement of concrete structures" University of Rhode Island.

[6] Rehman, H.A.A.(2012)"some properties of fiber reinforced no fine concrete" Al-Qadisiya Journal For Engineering Sciences, Vol. 5, No. 4, 439-450, Wasit university.

[7] Muttar, A.A.(2013) "Improving The Mechanical properties of Nofines concrete" Journal of Babylon University/ Engineering Sciences / No.(2)/ Vol.(21).

[8] Balendran R.V., F.P.Zhou, A.Nadeem, A. Y. T.Leung,(2002) "Influence of steel fibers on strength and ductility of normal and light weight high strength concrete " Building and Environment Vol. 37 (12) : 1361-1367.

[9] Chen B., J. Liu, (2004) "Properties of light weight expanded polystyrene concrete reinforced with steel fiber"Cement and Concrete research, Vol.34 (7) : 1259-1263).

[10] Iraqi Quality Standard No 5/1984 ( Portland Cement).

[11] Iraqi Quality Standard No 45/1984(Aggregate from Natural Sources for Concrete and Building Construction) .

[12] ASTM C1240 (2016) "Standard specification for use of silica fume as a mineral Admixture in Hydraulic Cement Concrete, Mortar, and Grout".

[13] Neville A.M. 2010 "properties of concrete", fifth edition.

[14] ASTM C 494(2017), "Standard specification for chemical admixtures for concrete"

[15] ACI committee 544( 2009), state of the Art Report on Fiber Reinforced concrete, ACI concrete Interational, 4(5):90-30

[16] Henger,C.H.(1981), worldwide fibrous concrete projects, ACI concrete International , 7(9): 13-19.

[17] ASTM C116 (1999),'Test method for compressive strength of concrete using portion of beams broken in flexural".

[18] ASTM C293 (2006), "Standard Test Method for Flexural Strength of Concrete", (Using Simple Beam with Center-Point Loading).

[19] ASTM C642,(2013) "Standard test method for density, absorption , and voids in hardened concrete".

[20] B.S.1881, Part 122,(1983) "Method for Determination of water Absorption", British Standards Institution. 